Journal Port Science Research $v o l: 2$, No:2, 2019

$\overline{\mathrm{PAPER}} \cdot$ Full original article online Free

\title{
The concept of sustainable development among middle school students
}

\author{
Rooa Mahdi Jabar Albaaj
}

Directorate of Baghdad Education Karkh III, Ministry of Education, Baghdad, Iraq albaajrooa@gmail.com

\section{مفهوم التنمية المستدامة لدى طالبات المرحلة المتوسطة \\ رؤى مهدي جابر البعاج \\ وزارة التربية، مديرية تربية بغداد الكرج الثالثة، بغداد، العراق \\ albaajrooa@gmail.com}

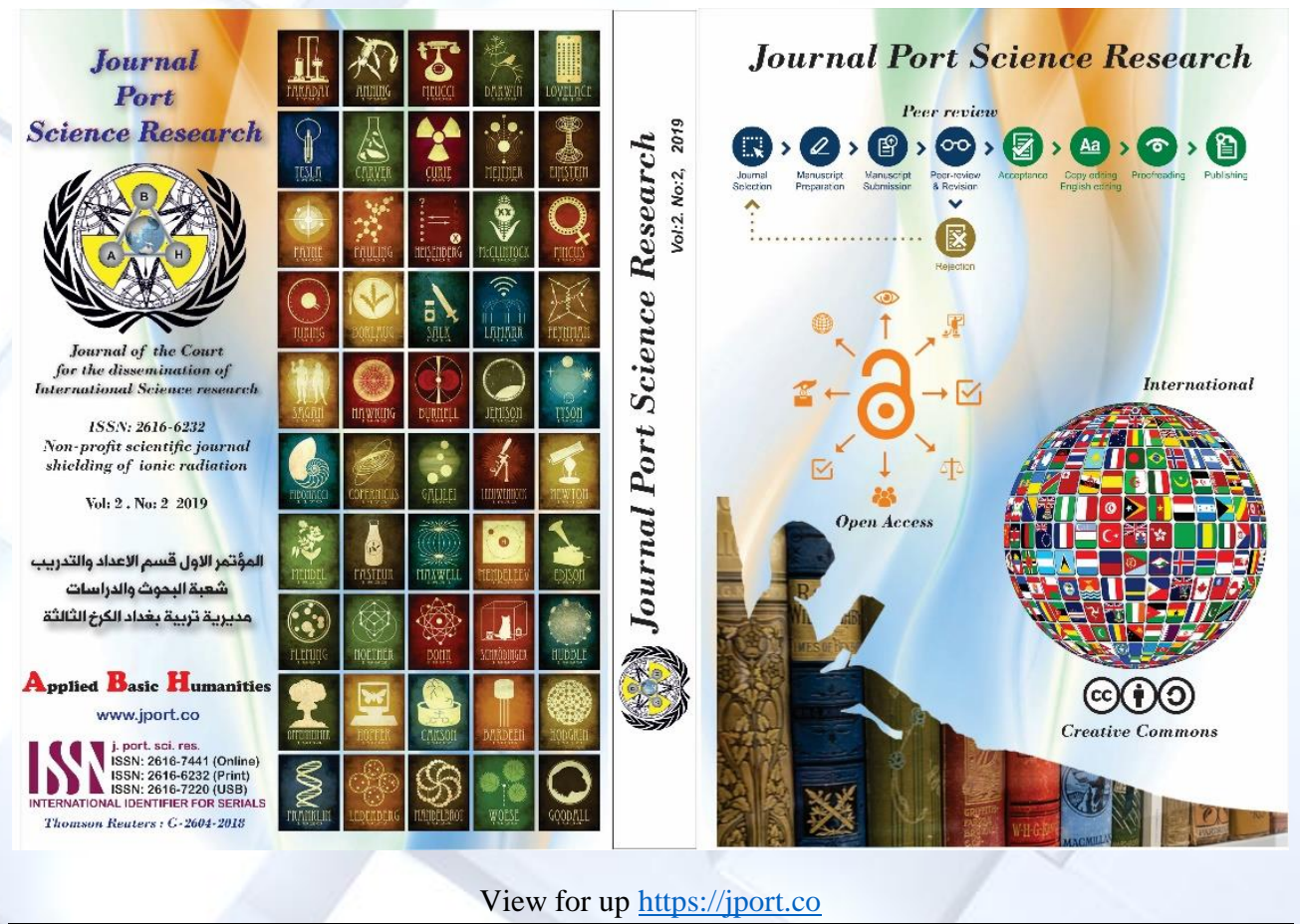

To cite this article: Published 2019 • C 2019 Bryant University United States of America Publishing Ltd. 
Ministry of Education Iraqi Directorate of Education Baghdad Karkh III

First Conference Department of Preparation and Training Division of Research and Studies

وزارة التريية العراقية مديرية تريية بغداد الكرخ الثالثة المؤتمر الاول قسم الاعداد والتلدريب شعبة البحوث واللدراسات

\title{
The concept of sustainable development among middle school students
}

\author{
Rooa Mahdi Jabar Albaaj \\ Directorate of Baghdad Education Karkh III, Ministry of Education, Baghdad, Iraq \\ albaajrooa@gmail.com
}

\begin{abstract}
To achieve the objectives, the researcher presented the general and theoretical framework and the methodology and procedures of the research. The sample selection where, the number of first-graders was (100) Student, And the number of third grade students (100) Student, the total sample of the research (200) students, the preparation of the scale consists of (24) paragraphs. He used statistical methods (spas) and the results were, and There are statistical differences between the first and third grade students in the middle and for the third grade and in the light of the results reached recommendations and proposals.
\end{abstract}

Keywords: Sustainable, development, environmental, Social, economic.

\section{مفهوم التنمية المستدامة للى طالبات المرحلة المتوسطة}

\author{
رؤى مهلدي جابر البعاج \\ وزارة التربية، مديرية تربية بغداد الكرج الثالثة، بغداد، العراق \\ albaajrooa@gmail.com
}

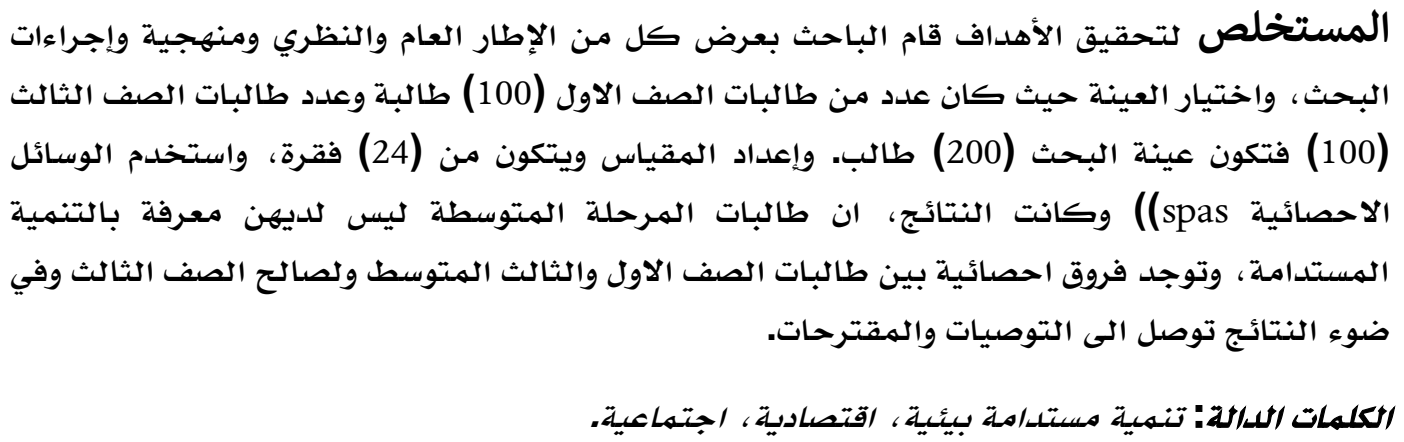

Albaaj, R. (2019). The concept of sustainable development among middle school students. Journal Port Science Research, 2(2), 287-303. 
تعد التنمية في فلسفتها مفهوم أخلاقي، فهي تعتمد على تغير في أنماط السلوك بحيث يتحمل الفرد مسؤولية الشعور بالآخرين من حوله ومن سيأتي بعده. فهي عملية ديناميكية مستمرة تنبع من الكيان وتشهل جميع الاتجاهات، فهي كعملية مطردة تهدف إلى تبديل الهياكل الاجتماعية وتعديل الأدوار والمراكز وتحريك الإمكانات المتعددة الجوانب بعد رصدها وتوجيهها نحو تحقيق هدف التغيير في المعطيات الفكرية والقيمية وبناء دعائم الدولة العصرية وذلك من خلال تكافل القوى البشرية لترجمة الخطط العلمية التنموية إلى مشروعات فاعلة تؤدي مخرجاتها إلى إحداث التغييرات المطلوبة [1]. كما ان مفهوم التنمية المستدامة يستند الى مجموعة من الضمانات التي تهدف الى تحقيق أهدافها والتي تشتمل على العوائد من التنمية ليشمل كل ما يعود على المجتمع بنفع بحيث لا يقتصر ذلك المفهوم علي العائد والتكلفة، استنادا إلي مردود الآثار البيئية الغير مباشرة وما يترتب عليها من كلفة اجتماعية، تجسد أوجه القصور في الموارد الطبيعية [2] فالتنمية المستدامة محورها هو الإنسان وتوفير الحياة الأفضل له وبالتالي فإن كل إنسان أيا كان موقعه سواء المواطن الذي يراعي احتياجاته واحتياجات أبنائه وجيرانه والمحيط الذي يعيش فيه أو كان الموظف الذي يؤدي واجبه بأمانة لتحقيق الأفضل لكل

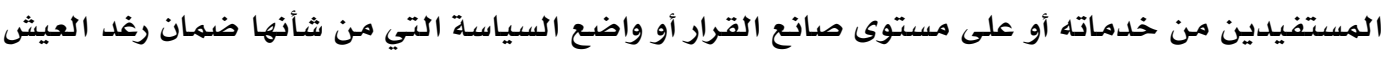
والقدرة على تلبية الاحتياجات للحاضر والمستقبل. فطالما محور التنمية المستدامـة هو الفرد واحتياجاته فإن الفرد أيضا هو الأساس في بناء هذه التنمية. لذلك تمثلت مشكلة البحث الحالي ما مستوى الفهم للطالبات المرحلة المتوسطة لمفهوم التنمية المستدامة على الرغم من اهتمام العديد من الدراسات بدور المناهج الدراسية في تنمية معارف واتجاهات نحو التنمية المستدامة مثل دراسة لوجينا والتي

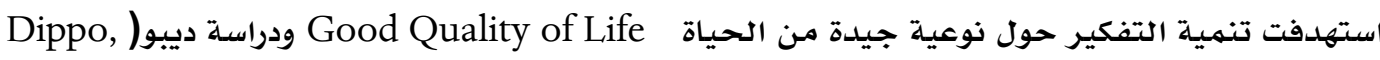

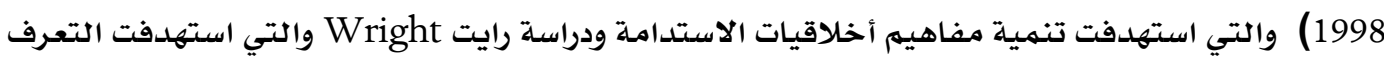
على الدور الذي تؤديه الجامعات في تحقيق مستقبل مستدام .ودراسة هاريس (Harris 2000) التي لتئي

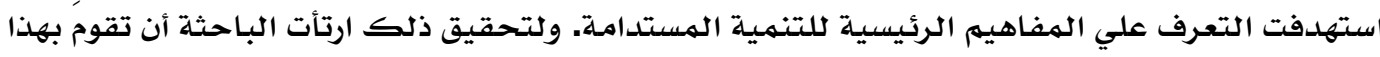
البحث علهُ يساهم في حل جزء من هذه المشكلة وهو الاجابة على التساؤل الاتي: مـا مدى مفهوم التنمية المستدامة عند طالبات المرحلة المتوسطة.

\section{•}

يعد موضوع التنمية المستدامة من الموضوعات الحيوية والأساسية في وقتنا الحالي والتي ينبغي أن تكون

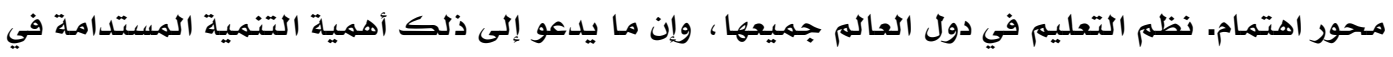
الخطط والمشاريع التنموية الاقتصادية والاجتماعية وحتى للتوعية والثقافة التي تخطط لها دول العالم

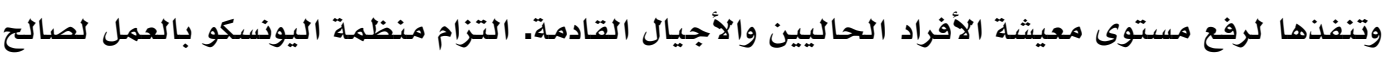

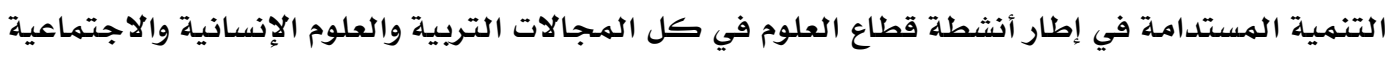
والثقافية والاتصال وعقد المؤتمر الأول للجمعية العامة للأمم المتحدة 2002 مؤتمر الأمم المتحدة 
للتعليه من أجل التنمية المستدامة، وعينت اليونسكو وكالة مسئولة عن الترويج لهذا الأمر. وأقر بناء عالم يتاح فيه لكل شخص فرصة الانتفاع بالتعليم واكتساب القيم وأنماط السلوك والاستهلاك وأساليب العيش وكل ما يلزم من أجل بناء مستقبل قابل للاستمرار، ولتحقيق عالم أفضل وبناءا عليه في هذا المنظور حددت الأهداف التالية: تسهيل إنشاء شبكات وروابط لتشجيع المبادلات والتفاعلات بين الأطراف الفاعلة في مجال التعليهم من أجل التنمية المستدامة.

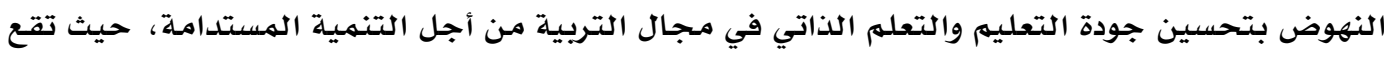

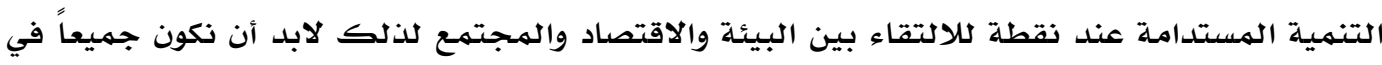
العالم أكثر وعياً واهتماماً بالبيئة والمشاكل المتعلقة بالاستهلاك لنتملك الماكئل المعرفة والمهارة والسبل

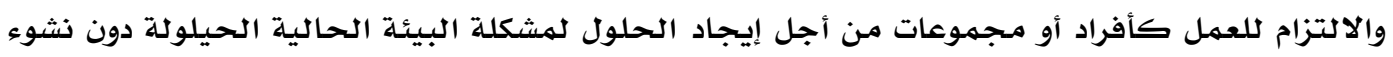
مشاكل جديدة للأجيال القادمة. ومن هنا يأتي دور العملية التعليمية بكل مؤسساتها الدور الرئيسي الذي تلعبه في الاهتمام بالمستحدثات

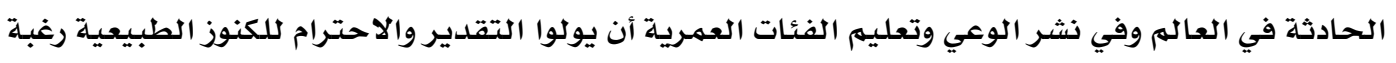

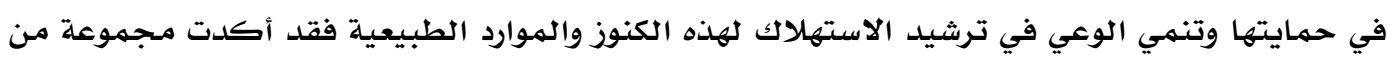
الدراسات أهمية إضافة مفاهيم ومهارات التنمية المستدامـة في المناهج والمقررات التعليمية في فئات

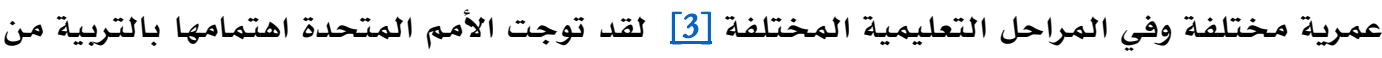

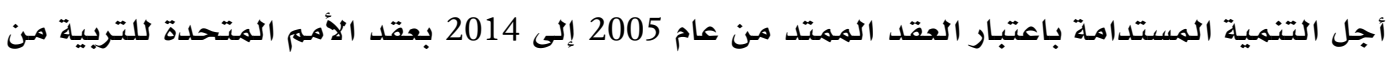
أجل التنمية المستدامة الذي يتطلب من جميع الدول في العالم أن تتخذ كافة الإجراءات والخطوط

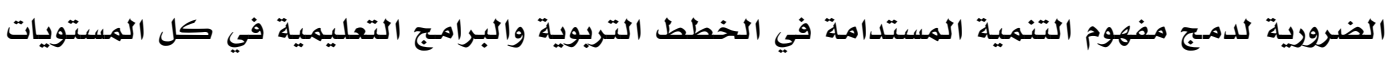

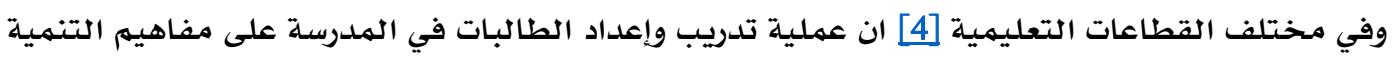

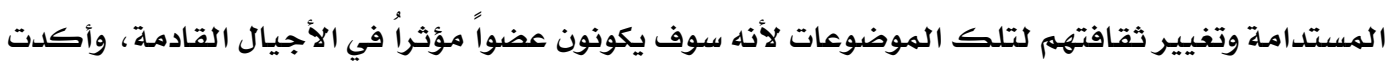
على ذلك دراسة عبد الله أبو سعيدي التي أثبتت أن التدريب والتعليم لهم أثر كبير في التنمية المستدامة للطلاب المعلمين في دول الخليج العربي [5] وقد حددت اليونسكو المقصود بالتعليهم من أجل التنمية

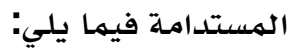
1) عليم ييسر للجميع الانتفاع بمختلف مستوياته أيا كان السياق الاجتماعي. 2) العليم يعد مواطنين يتحملون مسئولياتهم ويشجع على الديمقراطية لتحديد الواجبات والحقوق.

$$
\begin{aligned}
& \text { 3) تعليم يضمن تفتح كل شخص تفتحاً متوازناً. } \\
& \text { 4) العليم يدخل في منظور التعلم مدىى الحياة. }
\end{aligned}
$$

وحددت اليونسكو وحددت اليونسكو في النهاية دور تقنية المعلومات في تحقيق التنمية المستدامة في هذا العصر الذي تحدد فيه التكنولوجيات القرارات التنافسية حيث تستطيع تقنية المعلومات أن تلعب دوراً

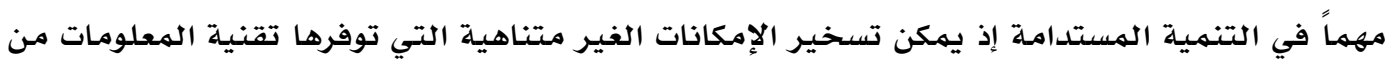
أجل إحلال تنمية مستدامة اقتصادية واجتماعية وبيئية.

Albaaj, R. (2019). The concept of sustainable development among middle school students. Journal Port Science Research, 2(2), 287-303. 
وذلك من خلال تعزيز التكنولوجيا من أجل التنمية المستدامـة كما يلي: 1) تعزيز أنشطة البحث والتطوير لتعزيز تكنولوجيا المعلومات والاتصالات.

2) تحسين أداء المؤسسات من خلال مدخلات معينـة مستندة إلى التكنولوجيات الحديثة. 3) تعزيز بناء القدرات في العلوم والتكنولوجيا والابتكار بهدف تحقيق أهداف التتميلة المستدامـة في الاقتصاد القائم على المعرفة ولاسيما أن بناء القدرات هو الوسيلة الوحيدة لتعزيز التنافسية

$$
\text { وزيادة النمو الاقتصادي وتوليد فرص عمل جديدة. }
$$$$
\text { 4) وضع خطط وبرامج تهدف إلى تحويل المجتهـع إلى مجتهـع معلوماتي. }
$$

5) إعداد سياسات وطنية للابتكار واستراتيجيات جديدة للتكنولوجيا مـع التركيز على تكنولوجيا

$$
\text { المعلومات والاتصالات [6] }
$$

إن أي تقدم نحو تحقيق مجتمـع مستدام يتطلب من كل أفراد ذلك المجتمـع أن يكونوا على إطلاع وفهم بما يعنيه المـجتهـع المستدام من خلال المعلومات والقيه والههارات التي يمتلكونها والتي تقدم لهم بطرق مختلفة رسمية كانت أو شبه رسمية أو حتى غير رسمية. ينظر للتنمية المستدامة (SD) على أنها رؤية أفضل للعالم الذي يتهم توازن الاعتبارات البيئية والاجتماعية والاقتصادية والثقافية، البيئة والتنمية المستدامة، تمثل أداة لتحقيق هذه الرؤية، وتحسين نوعية الحياة، ويتم تشكيل رؤية جديدة للتعليه، وهي الرؤية التي تساعد على فهم العالم من خلال معالجة التعقيد والترابط بين المشاكل اليومية، محليا وعلى

$$
\text { الصعيد العالهي [7]. }
$$

\section{• أهداف البحث}

استهدف البحث الحالي التعرف على: تحديد مستوى التنمية المستدامـة لدى طالبات المرحلة المتوسطة، تحديد الفروقات ذات الدلالة الإحصائية في مستوى مفهوم التنمية المستدامـة وفقاً للمرحلة الدراسية

$$
\begin{aligned}
& \text { (الاول، الثالث). } \\
& \text { حدود البحث } \\
& \text { يتحدد البحثث الحالي بـ }
\end{aligned}
$$

1) الحدود البشرية: طالبات المرحلة المتوسطة.

2) الحدود الزمانية: العام الدراسي (2017 - 2018).

3) الحدود الهكانية: بعض المدارس المتوسطة التابعة الى مديرية تربية بغداد/ الكرج3.

\section{تحلديل المصطلحات}

أولاً: التنمية عرفها علام التنمية لغة: هي الزيادة، والنـماء، والكثرة، والوفرة، والمضاعفة. التتمية اصطلاحاً: عبارة عن التغيير الإرادي الذي يحدث في المجتمـع سواءً اجتماعياً، أم اقتصادياً، أم سياسياً ، بحيث ينتقل من خلاله مـن الوضـع الحالي الذي هو عليه إلى الوضع الذي ينبغي أن يكون عليه، 
بهلدف تطوير وتحسين أحوال الناس من خلال استغلال جميع الموارد والطاقات المتاحة حتى تستغّل في

مكانها الصحيح، ويعتمد هذا التغيير بشكل أساسي على مشاركة أفراد المجتهـع نفسـ [8].

ثانيا التنمية المستدامة:

التتمية المستـامـة: هي السعي الدائم لتطوير نوعية الحياة الإنسانية مـع الأخذ في الاعتبـار قدرات وإمكانات النظام البيئي.

التعريف النظري وقد عرفت الباحثة التنمية المستدامـة هي قدرة المتعلم على معرفة معنى التنمية المستدامـة وفق ابعادها (البيئية والاقتصادية والاجتهاعية) والتفاعل معها من اجل تحمل الهسؤولية والشعور بالآخرين وتحقيق جودة الحياة. التعريف الاجرائي هي الدرجة التي تحصل عليها الطالبة من خلال استجابتها على فقرات مقياس التنمية المستـامـة الذي اعدته الباحثة في البحث الحالي.

\section{الإطار ر النظري ودراسات سابقة}

تعتبر التتميلة الهستدامـة أحد عناصر التتهية الشاملة الذي يعتبر الهفهوم الشامل لجميع الهـالات والاوجـه المختلفة للتنهية، لقد حلدث التطور في مفهوم التنهية بحيث انتقل من التركيز على الجوانب الاقتصادية إلى إعطاء أهمية للجوانب الاجتماعية والإنسانية بحيث تطور مفهوم التنمية الى التنمية البشرية اي انتقل مفهوم التنمية الى الحقل السياسي والثقافي والاجتماعي والبيئي واعتبر الانسان اداة وغاية التنمية وتعتبر التنمية مفهوم عام يدل على "التطور او التغير الجذري في مختلف الميادين الاقتصادية والاجتماعية والتربوية" [9]. "يفرق العلماء بين مفهوم النمو والتنمية، فالتنمية ترتبط دائماً بتغييرات جذرية في هيكل المؤسسـة نفسها وليس فقط على النتيجة كها هو الحال في النمو. أشكال التنمية الثقافيّة الفكريّة: هي التي تعتمد على تحسين ثقافة الأفراد وزيادة الوعي لديهم، ويكون ذلك من خلال عدة طرق منها تعميه التعليه للجميع ومحارية الأمية. التنمية الاجتماعيّة: تهدف إلى تحقيق الاستقرار الاجتماعي للأفراد وتشجيعهم على المشاركة بالمناسبات الاجتماعية، والأعمال الخيريّة، ونشر الروح الجماعية المشتركة فيما بينهم. التنمية السياسيّة: تهدف إلى زيادة قدرة الأفراد على المشاركة في العملية السياسية، وصنع القرارات، والقدرة على الاختيار السليه. التنمية الاقتصاديّة: تهدف إلى تشجيع الأفراد على العمل، والإنتاخ، والإخلاص في العمل النابع من الضمير الداخلي للشخص، والحرص على المصلحة العامـة. خصائص تنهية المـجتهـع عملية شاملة لجميع جوانب المجتمـع الاجتماعية، والاقتصادية، والثقافية، والإدارية، حيث تتعامل معه باعتباره نظاماً كاملاً ومتكامـلاً. عملية مستمرة، فلا تقف عند حد معين من التغيير، كما أنّ عملية تطبيقها للحصول على النتائج المطلوبة تحتاخ إلى وقت طويل؛ لأنّ التغيير يحصل في البنية الأساسيّة للمجتهـع. عملية مخططة، فلا يمكن البدء بأي شكل من أشكال التنمية إلا بعد تحديد الأهداف الرئيسية منها ، ولا يمكن تحقيق هذه الأهداف إلا من خلال عملية تخطيط ذات أسلوب علمي منظم. عملية استثماريّة؛ حيث ترتكز على استثمار الموارد البشريّة 
j. port. sci. res.
ISSN: 2616-744

والماديّة الهوجودة بهدف تحقيق النتائج. عملية إداريـة يرتكز النجاح فيها على كفاءة الإدارة في الدولة،

وبتعاون جميع المؤسسات فيها سواءً كانت حكوميّة أم خاصة [10].

نستطيع البحث في أصول التنمية الأولى منذ التجارب المبكّرة التي قام بها الإنسان الأوّل لإدراك التغيرات التي تحصل من حوله، وقد ارتبط ذلك بالتجارب الحية والتأمل في الاختلافات التي تحصل في الموجودات كفصول العام، والنبـات، والإنسـان، والحيوان. أكّدت تلك التغيّرات أنّ هذا العالم في حركة غير متوقفة وفي تغيّر مستهـر، وقد أدت هذه الملاحظات والتأملات إلى ظهور نقاث فلسفي حول مـاهية الأثياء، وطبيعة المتغيّرات التي تحدث فيها. مفهوم التنمية هي ارتقاء الهجتهـع والانتقال به من الوضع الثابت إلى وضع أعلى وأفضل، وما تصل إليه من حسن لاستغلال الطاقات التي تتوفّر لديها ، والموجودة والكامنة وتوظيفها للأفضل. التنمية لغة هي النمو وارتفاع الشيء من مكانه إلى مكان آخر. التنمية اصطلاحاً: هي عبارة عن تحقيق زيادة سريعة تراكميّة ودائمة عبر فترة من الزمن في الإنتاخ والخدمات نتيجة استخدام الجهود العلميّة لتتظيهم الأنشطة المشتركة الحكوميّة والشعبية. أشكال التنهية الشاملة، والمتكاملة، والتتمية في أحد الميادين الرئيسية، مثل: الميدان الاقتصادي أو السياسي أو الاجتماعي أو الميادين الفرعية؛ كالتتمية الصناعيّة، أو التنهية الزراعية، ويمكن القول إنّها عملية تغيير اجتماعي مـخطّط يقوم بها الإنسان للانتقال بالمجتمـع إلى وضع أفضل وبهما يتوافق مـع احتياجاته وإمكانيّاته الاقتصادية والاجتماعية والفكريّة. إنّ التنمية هي العمليّة التي تنتج عنها زيادة فرص حياة" بعض الناس في مجتهـع ما، دون نقصان فرص حياة بعضهم "الآخر في الوقت نفسه، والمجتمـع نفسه، وهي زيادة مـحسوسـة في الإنتاخ والخدمات شـاملة ومتكاملة ومـرتبطة بحركة المجتهمع تأثيراً وتأثراً، مستخدمةً "الأساليب العلمية الحديثة في التكنولوجيا والتنظيم والإدارة. التنمية عند هيئة الأمهم المتحدة هناك تعريف اصطلحت عليه هيئة الأمهم المتحلدة عام 1956 ينصِّ على أنّ التنمية هي العمليات التي بمقتضاها تُوجّه الجهود لكلٍٍ من الأهالي والحكومة بتحسين الأحوال الاقتصاديّة والاجتهاعية والثقافية في المجتمعات المحليّة؛ لمساعدتها على الاندماخ في حياة الأمهم والإسهام في تقدّمها بأفضل ما يمكن. الفلاسفة والتنمية الإغريق كان فلاسفة اليونان هم أوّل من ساهم في إظهار هذا الموضوع في ثقافة أوروبا ، ومنههم كان هرقليطس، الذي قال في فلسفته أموراً عن التغيير، وأوضتح أنّ العالم في تطوّر وتغير دائمين، وله مقولة شهيرة: إنك لا تستطيع أن تنزل في نفس النهر مرتين. وأوضح أن كل أمـر يتكون من متعاكسات (متقابلات) ، وينتج بذلك التوتّر الداخلي، أي للصراع. أرسطو تحدّث عن التغيّر من جانب آخر، فأوضـح طبيعة الدولة في كتاب السياسـة بوجود نظام في الكائن العضوي ينتقل من فترةٍ إلى أخرى؛ يبدأ بالولادة، فالنضج، وأخيراً الاضمحلال، والموت. العرب في القرن الرابع عشر قال بن خلدون: واعله أنّ اختلاف الأجيال إنما هو باختلاف نحلهم من المعاش، فإنّّ اجتماعهم في أحوالهم إنما هو للتعاون على تحصيله والابتداء بما هو ضروري من قبل الحاجي والكمالي، وكان حينئذٍ اجتماعهم وتعاونهم في حاجاتهم ومعاشهم وعمرانهم من القوة والذخيرة إنّما هو بالهقدار الذي يحفظ الحياة، ويحصل بُلغّة العيش من غير مزيد للعجز عمّا وراء ذلك، ثم إذا اتّسعت أموال هؤلاء المنتحلين للمعاش وحصل لهم ما فوق الحاجة من الغنى والرفاهيّة دعاهم ذلك إلى السكون والدعة". خلاصدة إنّ أهم أشكال التنمية هي البعاج، رؤى مهدي جابر. (2019). مفهوم التنمية المستدامة لدى طالبات المرحلة المتوسطة. Journal Port Science .303-287 ، (2)2 ، Research 
التنمية البشريّة كلإنسان وبالإنسان"، كلإنسان لنفسه الفاعلة ومعارفه المتغيّرة والمتجدّدة، وقدراته الماهرة، وعقله الذكي والفطن.

التطور التاريخي لمفهوم التنمية ان ثراء اللغة العربية بمفرداتها واشتقاقاتها جعل البحث في معنى مصطلح التنمية أمرا عقيما. لذا فان الاتفاق حول هذا المفهوم لا يكون الا من خلال الفهم التاريخي له ومتابعة

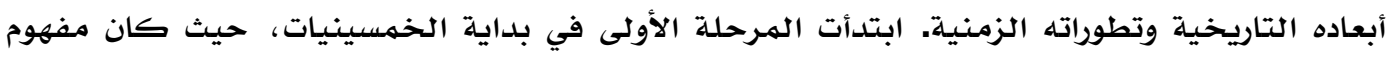
التنمية ينصب على الاستخدام الأمثل للموارد المتاحة بحيث يتسنى الحصول على اكبر إنتاخ بأقل كلفة الفيل وعرفت التنمية آنذاك بأنها تنشيط الاقتصاد القومي وتحويله من حالة الركود والثبات الى مرحلة الحركة والديناميكية عن طريق زيادة مقدرة الاقتصاد لتحقيق زيادة سنوية ملموسة في اجمالي الناتج

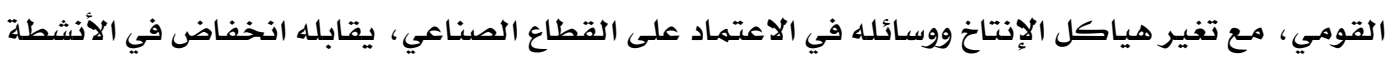

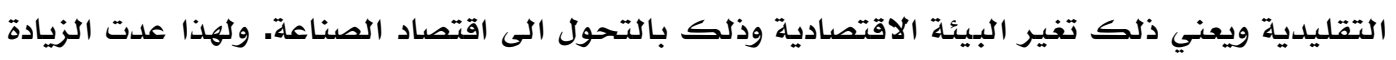

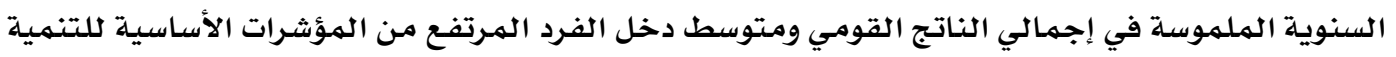
هناك ثلاثة أنواع من النمو: النمو التلقائي Spontaneous Growth والذي يحدث بسبب البعد الزمني،

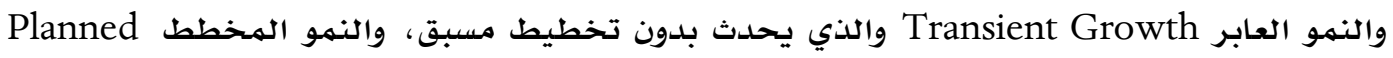
Growth

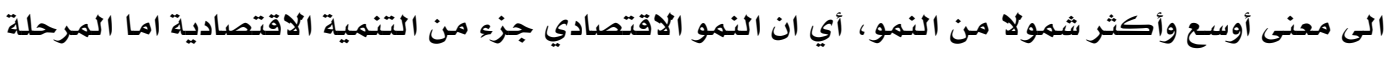

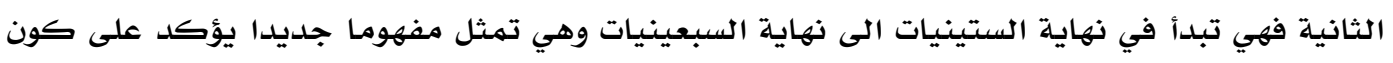
التنمية ليست حالة صماء يتم التعامل معها من خلال مؤشرات كمية اقتصادية او حتى مجتمعيدية.

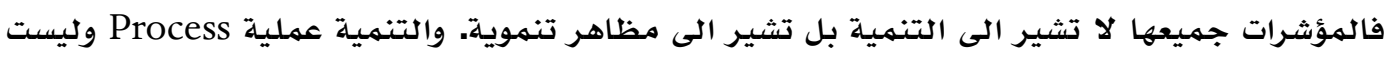

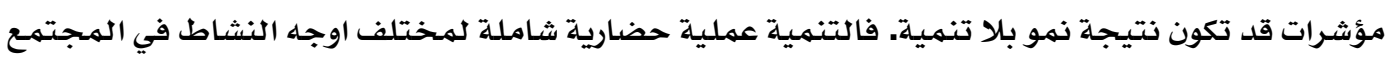
بما يحقق رفاه الإنسان وكرامته وهي بناء "كلإنسان وتحرير له وتطوير لكفاءاته وإطلاق لقدراته للعمل

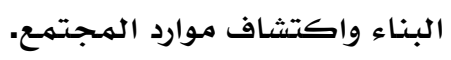
أهداف التنمية المستدامة يمكن الايضاح إن التنمية المستدامة تعتمد على أريع أهداف أساسية:

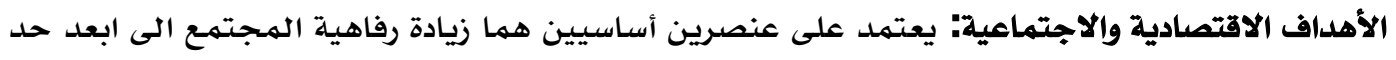

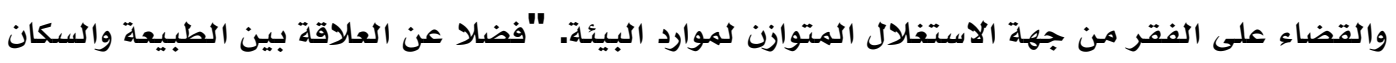

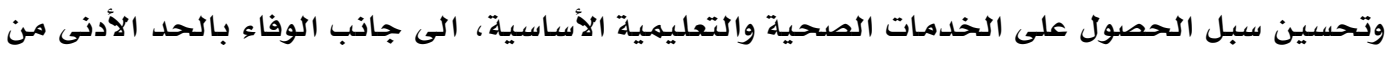
معايير الامن واحترام حقوق الإنسان والأهداف الجانبية الاخرى المتعلقة بتنمية الثقافات المختلفة والتنوع والتعددية والمشاركة الفعلية للقواعد الشعبية في صنع القرار".

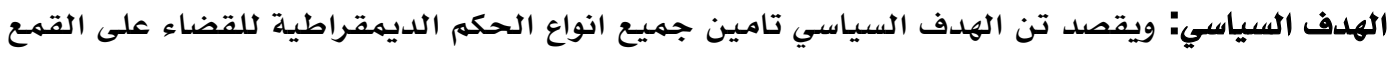
والاضطهاد العنصرية وان ننشر مفاهيم الديمقراطية وحرية الفكر والتعبير ومشاركة الأفراد في اتخاذ القرارات المصيرية والسياسية داخل المجتمع فضلا عن تحقيق المساواة بين الرجل والمرأة وإعطاء الأخيرة حقوقها لتأخذ دورها في المجتمحت.

Albaaj, R. (2019). The concept of sustainable development among middle school students. Journal Port Science Research, 2(2), 287-303. 

وإتباع الوسائل الحديثة للمحافظة على البيئة واجتناب الإسراف في استخدام الأسمدة والمبيدات حتى لا تؤدي الى تدهور الأنهار والبـحيرات والترية وتهدد الحياة البرية وتلوث الأغذية البشرية والإمدادات المـائية، فضلاً عن استخدام الري استخداما حذرا واجتناب تمليح أراضي المحاصيل وتشبعها بالماء الى جانب الابتعاد عن التجارب النووية ورمي النفايات في عرض البحار واستعمل الطاقة النظيفة والتوسع في استخدامها ، كما يشترط في التنهية المستدامة ان تستحوذ على قناعات الجماهير التي يجب ان تشترك في قراراتها ، الى جانب الهـردود الاقتصادي للها وقابليتها على اشباع الحاجات الإنسانية" [12]. اقترح ديلور (1996) الركائز الأساسية للتعليهم من أجل التنمية المستدامـة:

التعلم للمعرفة: يعني القدرة على التعلهم للحصول على معني للتعلم في جميع مراحل الحياة، وتطوير التفكير النقدي، والحصول على الأدوات اللازمـة لفهم العالم وفهم المفاهيهم والقضايا الاستدامـة. التعلم للعمل: يعني القدرة والفاعلية فضلا عن التفكير، والفهم والعمل على قضايا التنمية المستدامـة على الصعيد العالهي والهحلي، واكتسـاب التقنية والتدريب المهني، وتطبيق الهعرفة المكتسبة في الحياة اليوميلة، والقدرة على العمل الخلاق والمسؤولية تجاه البيئة. التعلم للعيث معا: يعني القدرة على المشاركة والتعاون مـع الآخرين في المجتمعات متعددة الثقافات، وتطوير فهم الأشخاص الآخرين والتقاليد والمعتقدات والقيه والثقافات، والاحترام والترحيب، واحتضان الفرق والتنوع بين الناس، والاستجابة بصورة بناءة للتنوع الثقافي والتفاوت الاقتصادي في جميع أنحاء العالهم والقدرة على التعامل مـع حالات التوتر والإقصاء والصراع والعنف والإرهاب" [13]. تعلم أن تكون: يعني القدرة على رؤية النفس لتحديد نتائج إيجابية للمستقبل، وتشجيع الاكتشاف والتجريب، اكتساب القيم المشتركة عالميا ، وتطوير الشخصية، والهوية الذاتية، والوفاء الذاتي وتكوين القدرة على العمل مـ حكم ذاتي أكبر، والحكمم والمسؤولية الشخصية. تعلم لتحويل الذات والمجتمع: يعني القدرة على العمل من أجل مجتمعات غير تمييزية بين الجنسين محايدة، وتطوير القدرة والإرادة لدمـج أنماط الحياة المستدامـة لأنفسنا والآخرين، وتعزيز السلوكيات والممارسـات التي تقلل من البصمة البيئية لدينا في العالم من حولنا، أن تحترم الأرض والحياة بكل

تنوعها ، والعمل لتحقيق التضامن الاجتماعي وتعزيز الديمقراطية في مجتمـع يسوده السلام [14]. التربية والتعليي من اجل التنمية المستدامة تسهم التربية والتعليهم أسـاهما ذو أهمية بالغـة في تحقيق التنمية المستدامـة من باعتبار أن التربية مفهوم ديناميكي يتضمن رؤية جديدة للتربية التي تستخدم للسعي لتعليهم الأشخاص من الفئات العمرية المـختلفة لأخذ الهمؤولية مـ اجل خلق مستقبل مستدام [15]. تسعى التربية من اجل التنمية المستدامة إلى إيجاد توازن بين الرخاء الإنساني والاقتصادي والتقاليد الثقافية، واستدامـة الموارد الطبيعية ، والبيئية من اجل حياة أفضل للفرد، والمجتمـع في الحاضر، ولكلأجيال القادمـة وتطبيق مبادئ التنمية المستدامـة يتطلب الاعتماد على منهجيات متعددة الأغراض والأساليب لتامين تعلهم أخلاقي مدى الحياة لجميع الفئات والمناطق وتشجيع احترام الاحتياجات الإنسانية التي تتوافق مع الاستخدام المستدام والتوازن للموارد

البعاج، رؤى مهدي جابر. (2019). مفهوم التنمية المستدامة لدى طالبات المرحلة المتوسطة. Journal Port Science .303-287 ، (2)2 2 Research 
الطبيعية والمحافظة عليها من اجل البشرية في حاضرها ومستقبلها وتغذي الحس بالتضامن على المستويات الوطنية والإقليمية والدولية. لذلك يستلزم من مؤسسات التربية والتعليم عمليات أساسية

تحسين التعليم الأساسي: بمعنى انه لابد من التركيز على التعليه الأساسي - باعتباره الأساس الذي يبنى عليه المراحل التعليمية التالية، والعمل على تحسينه وتطويره، وإبراز أهداف الاستدامة بداخله

والاهتمام باكتساب المتعلمين المهارات الأساسية التي تحقق لهم الاستدامة والتعلم مدى الحياة.

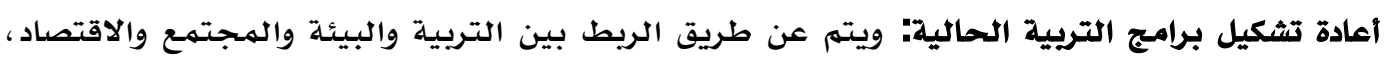
وتوفير متطلبات التنمية المستدامة من قضايا ومفاهيه ومهارات وتصورات وقيم وأنشطة تعليه وتعلهم

ببرامج التربية بحيث يتحقق المجتهمع الديمقراطي ونمط الحياة المستدام لجميع أفراد المجتمعح.

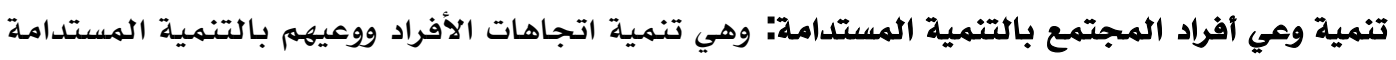

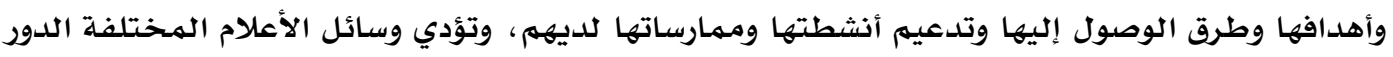

$$
\text { الأساسي في هذه العملية [16]. }
$$

التدريب على التعامل مع عمليات التنمية المستدامة وإداراتها وهي العملية التي يته من خلالها تدريب

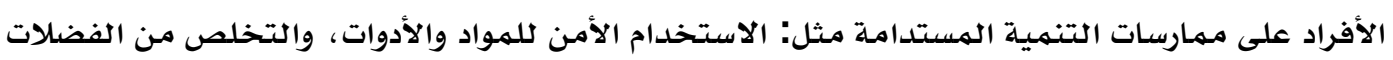

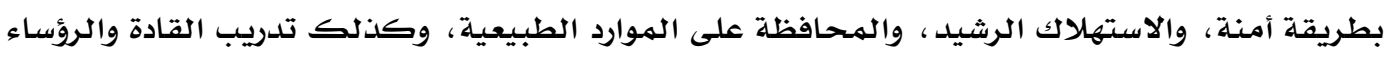

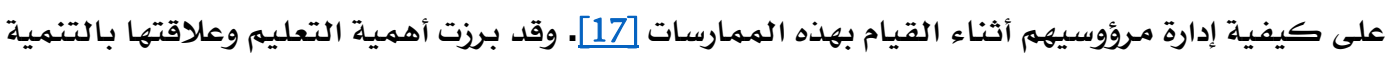
المستدامة بمجموعة محاور لخصت في إن التعليم من اجل التنمية المستدامـة:

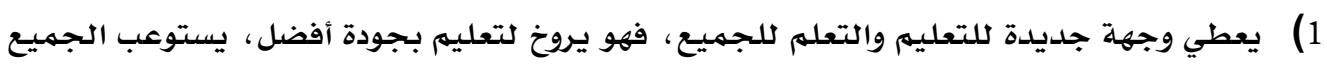

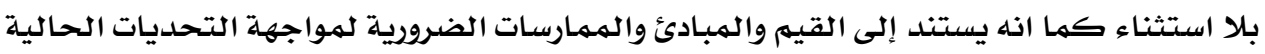
والمقبلة بصورة فعاله. 2) يجعل الأفراد ملتزمين أخلاقيا ويتمتعون بقدرات عالية، وشخصية، مكتملة، ومجتمع متعاون قائم على المشاركة والشفافية والعدالة، ويشدد على الترابط القائم بين البيئة والاقتصاد والمجتهمع 3) يشخص احتياجات الأفراد للتعلم والتعليهم والمضي قدما نحو صياغة أهدافهم وتوافر المصادر الملائمة لتحقيق هذه الأهداف وتطبيق استراتيجياتهم فضلا عن القيام بتقييم نتاخ العملية

$$
\text { التعليمية برمتها. }
$$

4) يقوم بدور مهم في تحقيق التنمية المستدامة وذلك من خلال أيجاد الحلول لجميع المشكلات

$$
\text { الدولية والمحلية على السواء. }
$$

5) يعمل التعليه على ترسيخ مفهوم التنمية المستدام في عقول الشعوب والأفراد الأمر الذي ينعكس النس

$$
\text { على تحقيق مفهوم جودة الحياة [18]. }
$$

لهذا فان التربية والتعليم من أجل التنمية المستدامة هو في جوهرة مسالة تتعلق بالقيم وتستند في صميمها إلى احترام الآخرين بما فيهم أجيال الحاضر وأجيال المستقبل واختلاف النوع واحترام البيئة

Albaaj, R. (2019). The concept of sustainable development among middle school students. Journal Port Science Research, 2(2), 287-303. 
واحترام موارد الكوكب الذي نعيث عليه، وان التعليهم يمكننا من فهم أنفسنا وفهم الآخرين وفهم الصلات التي تريط بيننا وبين البيئية الطبيعية والاجتماعي على نطاق واسع ويشكل هذا لهم أساسا مستداما لبناء الاحترام ويشمل التعليهم من اجل التنمية المستدامـة على تكوين قيم العدالة والمسؤولية والاستكشاف والحوار فانه يهدف أيضا إلى دفعنا إلى اعتهماد سلوكيات وممارسات يمكن الجميع من ان يحيوا حياتهم على أتم وجه وبدون أن يحرموا من الأساسيات [19].

\section{2. المنهجية والإجراءات}

إجراءات البحث يتضمن هذا الفصل تحديد مجتهـع البحث واختيار عينـة مـمثلة منـه لغرض تطبيق مقياس البحث، كما يتضمن اختيار أداة البحث والوسائل الاحصائية المتبعة التي استعملت في معالجـة البيانات وهي إجراءات اساسية يتبعها الباحث في تحقيق اهداف بحثه. منهج البحث اتبعت الباحثة منهج البحث الوصفي لأنه ينطبق على منهاخ بحثها ، فالبحث وفق هذا المنهج (الوصفي) والذي يعني استقصاء ظاهرة من الظواهر كما هي قائمة في الواقع بقصد تشخيصها وكشف جوانبها وتحديد العلاقات بين عناصرها أو بينها وبين ظواهر أخرى، وهذا مـا تقوم بـه الباحثة في منهاخ بحثها من جمـع المعلومات والحقائق عن التنمية المستدامـة لطالبـات المرحلة المتوسطة. مجتمع البحث يتحدد مجتهـع البحث الحالي من طالبـات المرحلة الهتوسطة لمدارس مديرية تربية الكرج الثالثة في مدينة بغداد (المدارس الصباحية) للعام الدراسي 2017 - 2018. عينة البحث اختارت الباحثة عينة البحث بالطريقة العشوائية المقصودة حيث تم اختيار متوسطتين من مديرية تربية الكرج الثالثة، ومن ثم تم اختيار العينة منها اذ بلغت (200) طالبـة، تم تحديد الاعداد بطريقة تناسبية، والمدارس هي: (خديجة الكبرىى، الزهراء) وتوزعت العينـة بحسب الهرحلة بواقع (100) طالبة من الصف الاول (100) طالبة من الصف الثالث والجدول (1) يوضح ذلك.

\begin{tabular}{|c|c|c|c|}
\hline العدد & & اسي المد & ت \\
\hline 100 & & متوسطة خديجة الكبرى & 1 \\
\hline 100 & & متوسطة الزهراء & 2 \\
\hline 200 & المجموع & & \\
\hline
\end{tabular}

تصميم اداة البحث: تحقيقا لأهداف البحث كان لا بد من استخدام أداة لقياس مفهوم التنمية المستدامـة عند طالبـات المـرحلة المتوسطة وفيها يأتي الإجـراءات التي اتبعتها الباحثة لإعداد هذه الأداة التي الهـراد استعمالها لقياس مفهوم التنمية المستدامة لدى الطالبات فقد قامت الباحثة ببنائها وذلك لأن الباحثة لهم تعثر على مقياس لهذا الهفهوم يتفق مـع أهداف البحث الحالي لذلك اتجهت الباحثة لبناء المقياس المذكور متبعتاً في ذلك الخطوات الآتية:

البعاج، رؤى مهدي جابر. (2019). مفهوم التنمية المستدامة لدى طالبات المرحلة المتوسطة. Journal Port Science ، .303-287 ، (2)2 Research 
تحديد العبارات التي يتضمنها المقياس وقد تم ذلك بعد رجوع الباحثة إلى عدد من الأدبيات ذات العلاقة بمفهوم التنمية المستدامة ومن هذه الادبيات توصلت الى تعريف وتم تحديد فقرات المقياس وفق ذلك التعريف الذي ينص على هي قدرة المتعلم على معرفة معنى التنمية المستدامة وفق ابعادها (البيئية

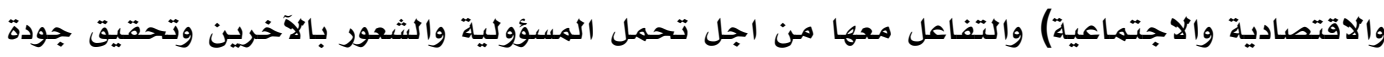

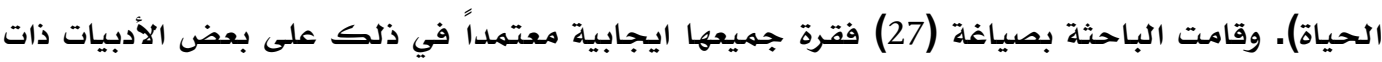
العلاقة بمفهوم التنمية المستدامـة. كما وضعت الباحثة ثلاثة بدائل على كل فله فقرة هي (دائما - أحياناً - لا) واعتمد مفتاح التصحيح (3 - 2 - 1)، وتهم تحديد مجالات المقياس وفق ابعاد مفهوم التنمية المستدامة مع تعريف لكل بعد منها وهي:

1) البعد البيئي: كل شيء محيط بالإنسان [20]. الرفاهية له [21]. 3) البعد الاجتماعي: هي القيم والاعراف والعادات والتقاليد والمعتقدات والانماط السلوكية والنظم الاجتماعية واعتنائها بالعنصر البشري. صلاحية الفقرات بعد الانتهاء من إعداد المقياس بشكله الأولي من حيث فقراته وبدائل الإجابة تم عرضهُ

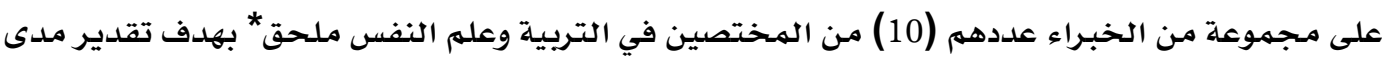
صلاحية الفقرات لقياس مفهوم التنمية المستدامة، وفي ضوء الملاحظات التي أبداها الخبراء، تم حذف لهاتف الفقرات التي لم تحصل على موافقة (80\%) فأكثر من الخبراء وقد حذفت ثلاث فقرات منه والإبقاء على (24) فقرة.

التحليل الإحصائي للفقرات تحليل الفقرات (القوة التميزية) لغرض استخراخ القوة التمييزية لفقرات المقياس قامت الباحثة باستخدام

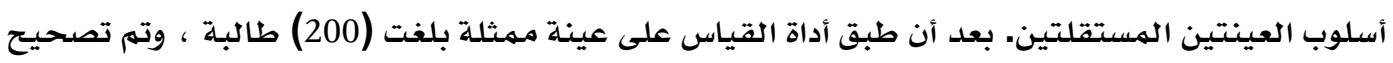

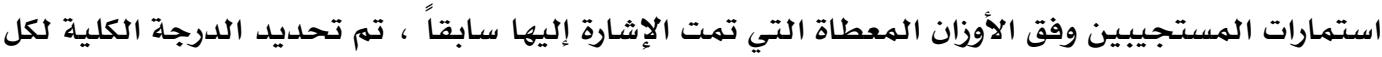

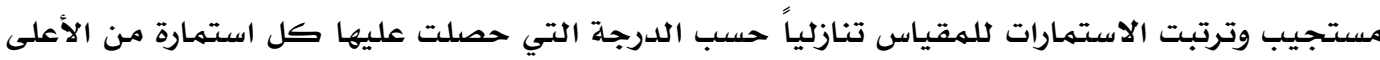

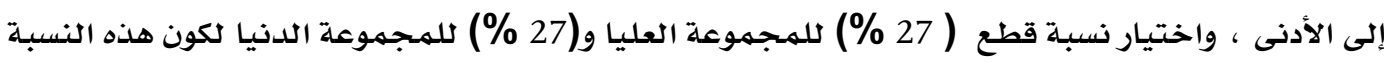
تعطي أكبر حجم وأقصى تمايز ممكن ، وفي ضوء ، هذه النسبة بلغ عدد الاستمارات التي خضعت للتحليل

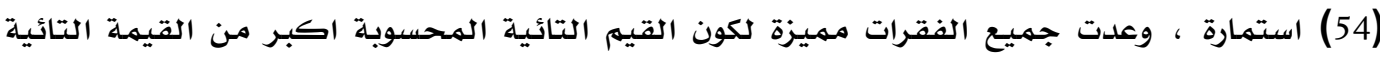

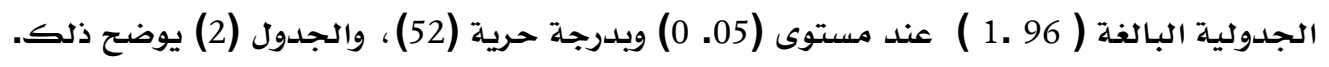

Albaaj, R. (2019). The concept of sustainable development among middle school students. Journal Port Science Research, 2(2), 287-303. 
الجلدول (2) القوة التميزية لفقرات الهقياس باستعمال أسلوب الهجموعتين المتطرفتين

\begin{tabular}{|c|c|c|c|c|c|c|c|c|c|c|c|}
\hline \multirow{2}{*}{ 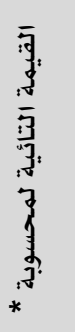 } & \multicolumn{2}{|c|}{ المجموعة الدنيا } & \multicolumn{2}{|c|}{ المجموعة العليا } & \multirow[b]{2}{*}{ ف ف } & \multirow{2}{*}{ 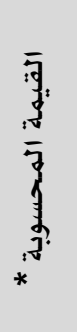 } & \multicolumn{2}{|c|}{ المجموعة الدنيا } & \multicolumn{2}{|c|}{ المجمهوعة العليا } & \multirow[b]{2}{*}{ ف } \\
\hline & معياري & $\begin{array}{l}\hat{\jmath} \\
\hat{3} \\
3\end{array}$ & معياري انحراف & $\begin{array}{l}\hat{\jmath} \\
\frac{1}{3}\end{array}$ & & & معياري انحراف & $\begin{array}{l}\hat{g} \\
\hat{j} \\
\dot{j}\end{array}$ & معياري & $\begin{array}{l}\hat{g} \\
\hat{j} \\
3\end{array}$ & \\
\hline 3.08 & 0.40 & 1.40 & 0.19 & 1.96 & 13 & 4.86 & 0.48 & 1.34 & 0.46 & 1.70 & 1 \\
\hline 8.81 & 0.35 & 1.14 & 0.45 & 1.72 & 14 & 8.81 & 0.35 & 1.14 & 0.45 & 1.72 & 2 \\
\hline 9.57 & 0.45 & 1.28 & 0.30 & 1.89 & 15 & 9.46 & 027 & 1.08 & 0.47 & 1.67 & 3 \\
\hline 4.98 & 0.41 & 1.21 & 0.49 & 1.58 & 16 & 7.87 & 0.40 & 1.19 & 0.44 & 1.73 & 4 \\
\hline 8.41 & 0.42 & 1.24 & 0.40 & 1.80 & 17 & 4.54 & 0.51 & 1.55 & 0.34 & 1.86 & 5 \\
\hline 4.60 & 0.41 & 1.21 & 0.50 & 1.55 & 18 & 5.54 & 0.48 & 1.36 & 0.42 & 1.77 & 6 \\
\hline 3.50 & 0.51 & 1.31 & 0.42 & 1.78 & 19 & 7.76 & 0.47 & 1.33 & 0.35 & 1.85 & 7 \\
\hline 2.29 & 0.32 & 1.12 & 0.44 & 1.26 & 20 & 5.48 & 0.44 & 1.26 & 0.47 & 1.67 & 8 \\
\hline 3.08 & 0.40 & 1.41 & 0.19 & 1.96 & 21 & 3.81 & 0.48 & 1.44 & 0.31 & 1.89 & 9 \\
\hline 6.31 & 0.50 & 1.49 & 0.29 & 1.91 & 22 & 3.51 & 0.50 & 1.51 & 0.42 & 1.77 & 10 \\
\hline 4.90 & 0.49 & 1.38 & 0.44 & 1.75 & 23 & 4.86 & 0.48 & 1.34 & 0.46 & 1.70 & 11 \\
\hline 4.43 & 0.48 & 1.42 & 0.29 & 1.90 & 24 & 8.81 & 0.35 & 1.14 & 0.45 & 1.72 & 12 \\
\hline
\end{tabular}

علاقة درجة الفقرة بدرجة المقياس الكلية تم احتساب صدق الفقرات المحك الداخلي (علاقة درجة الفقرة

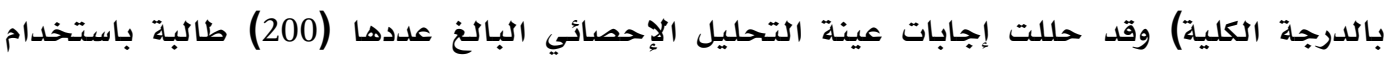

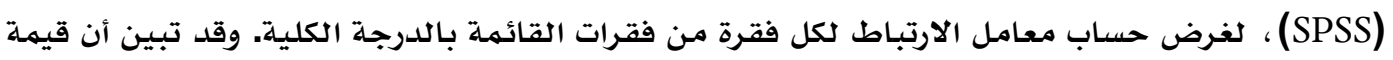

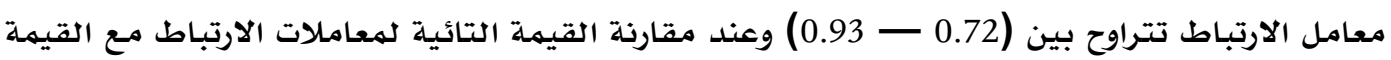

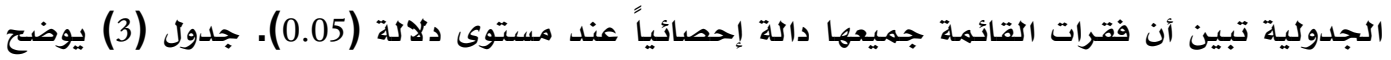

الجلدول (3) معاملات ارتباط درجة الفقرة بالدرجة الكلية لهقياس التنمية الهستدامة

\begin{tabular}{|c|c|c|c|c|c|c|c|}
\hline معامل الارتباط & الفقرة & معامل الارتباط & الفقرة رقم & الارتبـاطل & الفقرة رقم & الارتباطل & الفقرة رقم \\
\hline 0.91 & 19 & 0.76 & 13 & 0.83 & 7 & 0.86 & 1 \\
\hline 0.91 & 20 & 0.87 & 14 & 0.72 & 8 & 0.88 & 2 \\
\hline 0.91 & 21 & 0.90 & 15 & 0.82 & 9 & 0.91 & 3 \\
\hline 0.95 & 22 & 0.93 & 16 & 0.91 & 10 & 0.91 & 4 \\
\hline 0.92 & 23 & 0.93 & 17 & 0.77 & 11 & 0.89 & 5 \\
\hline 0.93 & 24 & 0.92 & 18 & 0.82 & 12 & 0.91 & 6 \\
\hline
\end{tabular}


أولا الصدق من الشروط الضرورية واللازمة لبناء الاختبارات والمقاييس وهو خاصية سايكومترية تكثف لفرفي

عن مدى تأدية المقياس للغرض الذي اعد من اجله 22. وقد تم التحقق من خلال نوعين من الصدق. أ- الصدق الظاهري للمقياس يعد الصدق الظاهري المظهر العام للقياس وهو يشير إلى ما يبدو

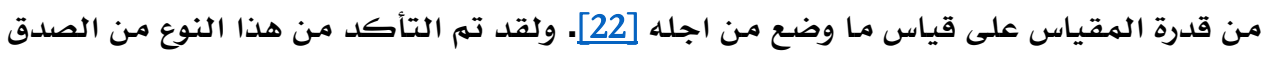

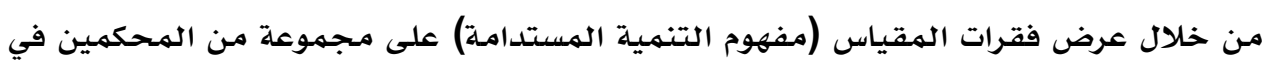

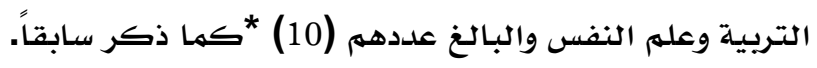

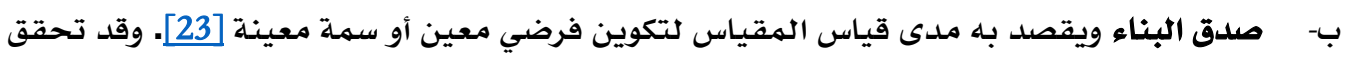
الصدق البنائي من خلال مؤشرات تمييز الفقرات وعلاقة درجة الفقرة بالدرجة الكلية لمقياس

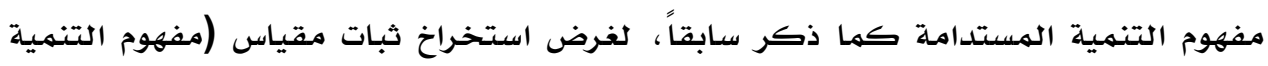
المستدامـة) قامت الباحثة باستعمال عدة طرق وهي: طريقة التجزئة النصفية وهي من أكثر الطرق استخداما في البحوث النفسية، وتعتمد أساساً

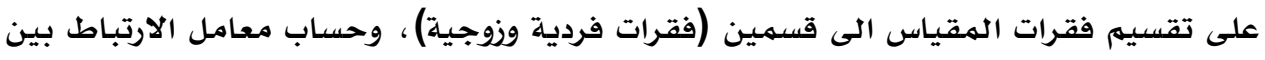

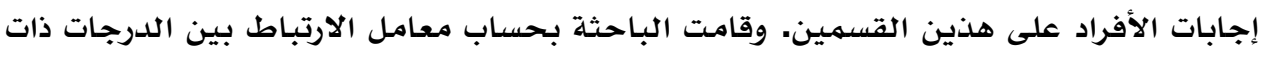

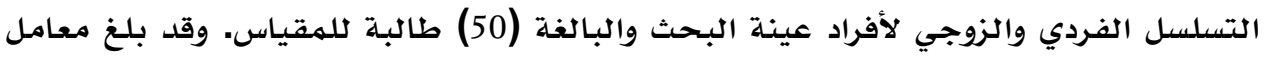

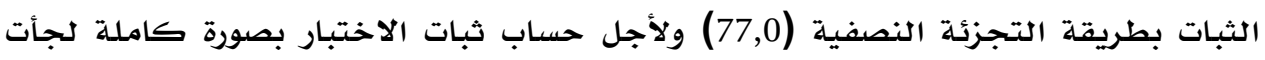

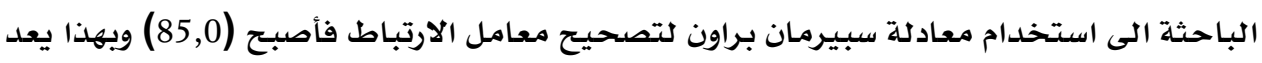
المقياس ثابت. طريقة إعادة الاختبار وقد تم اختيار عينة عشوائية وعددها (50) وطالبة من عينة التحليل الاحصائي، تم تطبيق المقياس على أفراد العينة، وبعد مرور مدة أسبوعين على التطبيق الأول، أعيد تطبيق المقياس من قبل الباحثة مرة أخرى على نفس العينة، ثم صححت إجاباتهم، لهمئ،

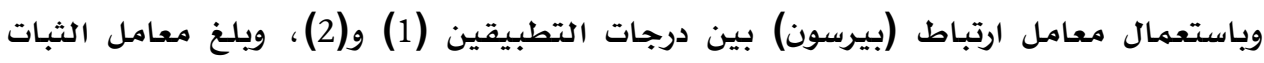

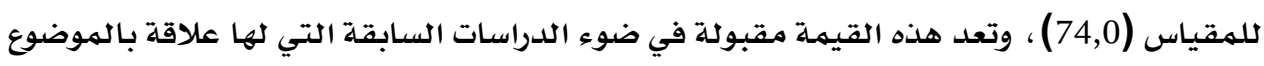
وصف المقياس مفهوم التنمية المستدامة بصيغته النهائية يتألف مقياس مفهوم التنمية المستدامة بصيغته النهائية من (24) فقرة، تتراوح الدرجة الكلية للمقياس من أدنى درجة إلى أعلى درجة (24-72) ،

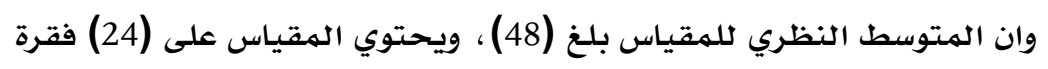

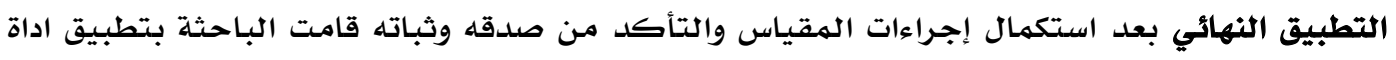

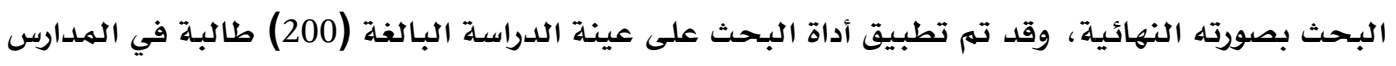

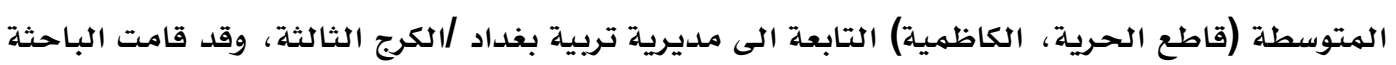
بتوضيح طريقة الاجابة على المقياس لإفراد العينة حيث استغرقت فترة التطبيق من 2018/2/13 الى الى $.2018 / 2 / 25$

Albaaj, R. (2019). The concept of sustainable development among middle school students. Journal Port Science Research, 2(2), 287-303. 
1) الاختبار التائي لعينتين مستقلتين .2- معامل الاتيه ارتباط بيرسون. 2) معامل سبيرمان براون للتصحيح 4 - الاختبار التائي لعينة واحدة.

\section{3. التحليل ومرض النتائج}

لقد تضمن هذا الفصل عرضاً للنتائج التي توصل إليها البحث الحالي على وفق أهدافه المرسومة، ومناقشة تلك النتائج وتفسيرها، ومن ثم الخروخ بتوصيات ومقترحات في ضوء تلك النتائج، وكما يأتي:

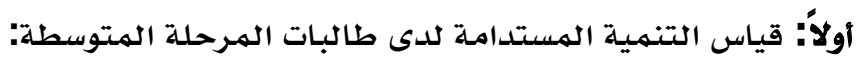
لقياس التنمية المستدامة للطالبات المتوسطة طبق المقياس على عينة البحث واستعمل الاختبار التائي لعينة واحدة، وتبين أن قيمة المتوسط الحسابي بلغت 37,39 والانحراف المعياري بلغت قيمته 7,82، وبعد مقارنة هذا المتوسط بالمتوسط الفرضي للاختبار البالغ48 ظهر إن القيمة التائية المحسوبة29,29وهي أعلى من القيمة التائية الجدولية البالغة 1,96 ولصالح الوسط الفرضي عند مستوى دلالة

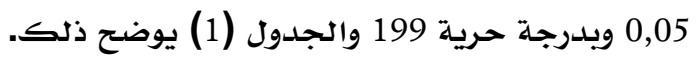

جلسول (1) القيه التائية الهحسوبة والجبلولية لهقياس مفهوم التنمية الهستلامة للى الطالبات المتوسطة

\begin{tabular}{|c|c|c|c|c|c|c|}
\hline مستوى الدلالة & القيمـة التائية & القيمة التائية & المتوسط & الانحراف & المتوسط الحسابي & العلدد \\
\hline دالة لصالح الوسط & 1,96 & 19,29 - & 48 & 7,82 & 37,39 & 200 \\
\hline
\end{tabular}

وتشير النتيجة الى أن الطالبـات ليس لديهن فهم ومعرفة لمفهوم التنمية المستدامـة وهذا يدل على ان الطالبـات لن يتلقن معلومات تعرفهن بأبعاد التنمية المستدامـة وشعورهن بعدم الرضا وتحقيق المعنى في الحياة وقد يعود السبب في ذلك للظروف القاهرة التي يمـر بها المجتمـع العراقي وهذا امر طبيعي لعدم قدرتهم على تحقيق اهدافهن ومنها جوانب الحياة الضروريـة والتي تعد الهدف الذي يستحق أن يعيشوا من أجله. وليس لديهم إدراك حقيقي لتقييم الأحداث وما يترتب عليها من عواقب سلبية وكذلك لن يصلن الى النضـج الكافي لمعرفة الرؤية وأنهن ليس لديهن فهم لإبعاد التنميلة المستدامـة وهي البيئية والاجتماعية والاقتصادية.

ثانيا: التعرف على الفروق في قياس مفهوم التنمية المستدامة لدى طالبـات المرحلة المتوسطة على وفق

$$
\text { متغير الصف الدراسي (الاول - الثالث). }
$$

تحقيقاً لهذا الهدف لجأت الباحثة إلى تصنيف عينـة البحث على وفق متغير الصف الدراسي إذ بلـغ عدد الصف الاول (100) طالبة والصف الثالث (100) طالبة، إذ قامت الباحثة باستخراخ المتوسط الحسابي 
والانحراف المعياري لدرجات الصف الاول والثالث، وتم اعتماد الاختبار التائي لعينتين مستقلتين فكانت

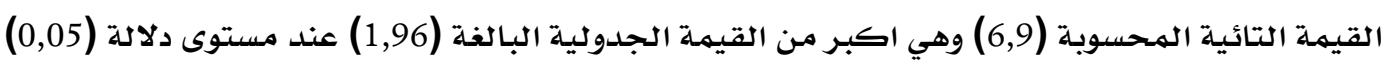

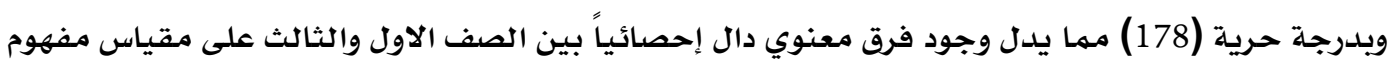

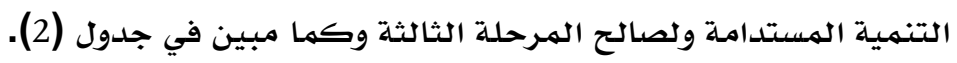

جلدول (2) يوضح الهتوسط الحسابي والانحرافات المعياريية للطالبات وفقًا لمتغير المرحلة (الاول - الثالث)

\begin{tabular}{|c|c|c|c|c|c|c|c|}
\hline \multirow{2}{*}{ الإحصائية (0,05) } & \multicolumn{2}{|c|}{ القيمة التائية } & \multirow{2}{*}{ الحرية } & \multirow{2}{*}{ الانحراف } & \multirow{2}{*}{ الحسابي } & \multirow{2}{*}{ المرحلة } & \multirow{2}{*}{ العددد } \\
\hline & الجدولية & المحسوبة & & & & & \\
\hline \multirow{2}{*}{ المرحلة الثالثة } & \multirow{2}{*}{1,96} & \multirow{2}{*}{6,88} & & 9,17 & 33,54 & الاول & 100 \\
\hline & & & & 6,47 & 41,22 & الثالث & 100 \\
\hline
\end{tabular}

إن النتائج التي يظهرها جدول (2) تشير إلى أن هناك الفرق بين المرحلة الأولى والثالثة ولصالح المرحلة

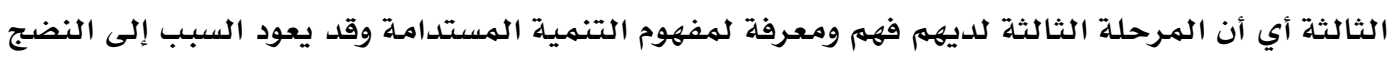
الذي وصلن أليه وكذلك المعلومات التي اكتسبتها الطالبات في المرحلة الدراسية وهي المتوسطة وهن

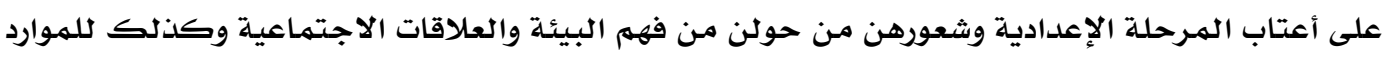

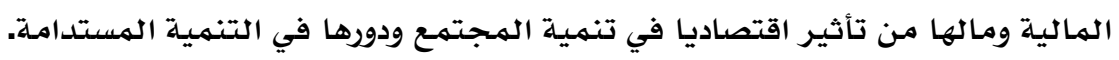

\section{4. الاستنتاجات}

يبدو ومن اجابات الطالبات وخاصة من المرحلة الاولى بأنهن اظهرن عدم قدرتهن على معرفة مفهوم التنمية المستدامة وقد يعود ذلك لعدم وصلهن الى حالة النضج وكذلك عدم قدرتهن على توظيف ما تعلمهن من معلومات دراسية لفهم هذا المفهوم، ومن خلال ايجاد الفروق بين المرحلة الاولى والثالثة فقد اظهر لصالح المرحلة الثالثة وهذا امر طبيعي نتيجة لوصول الطالبات الى مرحلة النضج واكتساب المعلومات الدراسيـة مها جعلت تفكيرهن وفهمن للتنميـة المستدامـة.

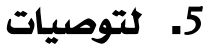

ضرورة تبني وزارة التربية مبادئ وأهداف التعليهم من اجل التتهية المستدامـة في المناهـج الدراسية بشكل واضح وذلك لتعريف الطلبـة بالتنمية المستدامـة والإفادة من تجارب الدول الأخرى التي سبقتنها في هذا المجال، ضـرورة تعاون المؤسسات التربوية والإعلامية في توضيح أهمية التتميلة المستدامـة في حياة المجتمعات وتطويرهم، ضرورة تدريب المعلمون والمدرسون على كيفية توظيف المواد التعليمية والتربوية مـن اجل توضيح مفهوم التنمية الهستدامسة للطلبة، لابد ان يعتمد المعلمون والمدرسون أنشطة تعليمية صفية والكلاصفيلة من اجل ريط التعلهم بالحياة اليومية للتلاميذ والطلبـة مـع مـراعاة العمـر الزمني للمتعلم من اجل توضيح التتمية المستدامهة ودورها في الحياة.

Albaaj, R. (2019). The concept of sustainable development among middle school students. Journal Port Science Research, 2(2), 287-303. 


\section{References}

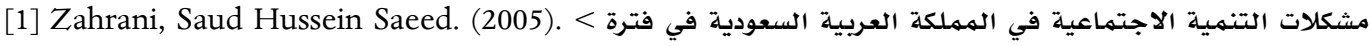
التخطيط التنموي في مجالات التربية و التعليه و الثقافة > The literary club in Al-Baha. https: / cutt.us / qnYWZ

[2] Ibrahim, Mohamed Ibrahim Jabr. (2008). مفاهيم التنمية المستدامة من منظور إسلامي: دراسة في ضمانات الإدارة الحضرية المتواصلة للمدينة الإسلامية . Journal of the Federation of the Universities of the Islamic World, Volume 2008, No. 6, p. 163-212, 50 p. https://search.emarefa.net/ar/detail/BIM$\underline{90760 ? \text { index }=2}$

[3] Khattab, Arkan Said. (2019). الاصلاح التربوي في العراق بين فلسفة تربوية رشيدة واستراتيجية واضحة المعالم> Ministry of higher education and scientific research, No, 1816, p 63-84. https: / / www.iasj.net/iasj?func $=$ article\&aId $=161552$

[4] Maclean, R., \& Ordonez, V. (2007). Work, skills development for employability and education for sustainable development. Educational Research for Policy and Practice, 6(2), 123-140. https: / / doi.org/10.1007/s10671-007-9017-y

[5] Al Lamloumi, Aljilani. Ali, Mohammed Jabbar. And others. (2006). دور التعليم والتدريب في التنمية > Beirut: المستدامة: الأبعاد الاجتماعية والاقتصادية والبيئية ، سلسلة دراسات التعليم والتدريب التقني والمهني UNESCO Regional Office, Arabic Version, https: / / www.gcedclearinghouse.org/ sites/default / files / resources / The $\% 20$ role $\% 20$ of $\% 20$ education \%20and $\% 20$ training $\% 20$ in $\% 20$ sustainable $\% 20$ development.pdf

[6] UNESCO Regional Bureau for Education in the Arab States (Beirut). (2008). Regional guiding framework of education for sustainable development in the Arab Region. UNESCO Regional Bureau for Education in the Arab States - Beirut. http://search.shamaa.org/FullRecord?ID=77525

[7] Nasibulina, A. (2017). Education for sustainable development. In Advances in Intelligent Systems and Computing (Vol. 498, pp. 947-954). Springer Verlag. https://doi.org/10.1007/978-3-319-42070$\underline{7 \_} 87$

[8] Allam, Saad Taha. (2006). التنمية ... و المجتمع > . Cairo: Arab House for Printing and Publishing, Madbouli Library. https:// cutt.us/BtUzQ

[9] Abdel Hafez, Hosny. (2011). رحلات ممتعة من المعرفة والأنشطة التريوية... الويب كويست > Retrieved. Date of April 2019, from, http:/ / www.almarefh.net/show_content_sub.php?CUV=381\&SubModel=135\&ID=982

[10] McCollum, D. L., Echeverri, L. G., Busch, S., Pachauri, S., Parkinson, S., Rogelj, J., ... Riahi, K. (2018). Connecting the sustainable development goals by their energy inter-linkages. Environmental Research Letters. Institute of Physics Publishing. https: / / doi.org/10.1088/1748-9326/ aaafe3

[11] Ercan, O. (2014). Effect of Web Assisted Education Supported by Six Thinking Hats on Students' Academic Achievement in Science and Technology Classes. European Journal of Educational Research, 3(1), 9-23. https:// doi.org/10.12973/eu-jer.3.1.9

[12] Al-Ghani, Ammar Abdul. (2017). خرافات التنمية البشرية> > Nile Arab Publishing Group, 1. https://www.goodreads.com/book/show/34331900

البعاج، رؤى مهدي جابر. (2019). مفهوم التنمية المستدامة لدى طالبات المرحلة المتوسطة. Journal Port Science ، 303-287 ، (2)2 ، Research 
[13] Ibrahim, Bassam Abdullah Taha. (2009). التعلم المبني على المشكلات الحياتية وتنمية التفكير> Al . Masirah Publishing \& Distribution House, 1. https:// cutt.ly/jwrKgCF

[14] United Nations Educational scientific and cultural organization. (2005). Unesco and Sustainable Development. Sustainable Development, $44 . \quad$ Retrieved from http: / / unesdoc.unesco.org/images/0013/001393/139369e.pdf

[15] Taroudi, Tariq Ali. (2011). Development upper basic stage social studies textbooks in Jordan in the light of population sustainable development indicators and measuring its effectiveness in students; attitudes towards demography education. (PhD Thesis), Yarmouk University, Faculty of Education, Jordan. http: / thesis.mandumah.com/Record/222137

[16] Tjoa, A. M., \& Tjoa, S. (2016). The role of ICT to achieve the UN sustainable development goals (SDG). In IFIP Advances in Information and Communication Technology (Vol. 481, pp. 3-13). Springer New York LLC. https: / / doi.org/10.1007/978-3-319-44447-5_1

[17] Nasibulina, A. (2017). Education for sustainable development. In Advances in Intelligent Systems and Computing (Vol. 498, pp. 947-954). Springer Verlag. https://doi.org/10.1007/978-3-319-42070$\underline{787}$

[18] Zayer, Saad Ali. Sabri, Abdul Salam. Hassan, Mohamed Hadi. (2014). طرائق التدريس العامة > Amman: Dar Safaa Publishing \& Distribution, 1. http://www.philadelphia.edu.jo/newlibrary/201411-24-13-12-11/530-2014-11-22-19-58-00/78035-76748

[19] Adeeb, Abdul Salam. (2002). أبعاد التنمية المستدامة_> Civilized Dialogue - Issue: 333. http:/ / www.ahewar.org/debat/show.art.asp?aid=4305

[20] Taher, Kadri Muhammad. (2013). التنمية المستدامة العربية بين النظرية والتطبيق> >. Briot: Hassan Al Asriya Bookshop, for printing and publishing, 1. https: / / www.neelwafurat.com/itempage.aspx?id=lbb219434-194980\&search=books

[21] Tuwayl, Fethiye. (2012) التربية البيئية ودورها في التنمية المستدامة-دراسة ميدانية بمؤسسات التعليم المتوسط

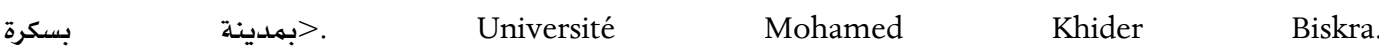

https: / / scholar.google.fr / scholar?oi=bibs\&cluster=6830887624928842081\&btnI=1\&hl=fr

[22] Perkins, D., \& Bishopp, D. (2017). Psychological testing. In Forensic Psychiatry: Fundamentals and Clinical Practice (pp. 559-565). Taylor and Francis. https:/ / doi.org/10.1201/9781315380797

[23] Melhem, Sami Mohammed. (2017). القياس والتقويم في التربية وعلم النفس> >. Dar Al - Masirah For Printing \& Publishing, 8(1). https://www.neelwafurat.com/itempage.aspx?id=1bb13429194482\&search=books 